\title{
Identifying the primary oxidation processes for particulate sulfide using mechanistic models of reducing microenvironments in large, sinking particles
}

\author{
NATALYA EVANS ${ }^{1}$, DANIELE BIANCHI ${ }^{2}$, GREGORY
}

CUTTER $^{3}$ AND JAMES MOFFETT ${ }^{1}$

${ }^{1}$ University of Southern California

${ }^{2}$ University of California Los Angeles

${ }^{3}$ Old Dominion University

Presenting Author: n.evans@usc.edu

The presence of reducing microenvironments in large sinking particles is a controversial topic in chemical oceanography with implications for carbon cycling, organic matter preservation, and trace metal speciation. Several studies have examined particulate sulfide and sulfate reduction rates in Oxygen Deficient Zones (ODZs) but have drawn different conclusions regarding the existence reducing microenvironments. Using the size-resolved particle model (PRiSM) implemented in Bianchi et al. (2018) [1] to predict sulfate reduction rates, we re-examine particulate sulfide measured during GP16 in the Peruvian ODZ [2]. In situ dissimilatory sulfate reduction best explains the particulate sulfide distribution observed on GP16, rather than assimilatory processes or offshore transport from shelf waters. These data allow us to constrain this model to observations and test parameterizations for sulfide loss, such as abiotic oxidation with water column compounds or biotic oxidation by chemoautotrophs. This model also enables us to estimate the rate of organic matter respiration via sulfate reduction relative to aerobic processes and the amount of carbon remineralized through this pathway.

[1] Bianchi, D., Weber, T. S., Kiko, R., \& Deutsch, C. (2018). Global niche of marine anaerobic metabolisms expanded by particle microenvironments. Nature Geoscience, 11(4), 263-268.

[2] Ohnemus, D. C., Rauschenberg, S., Cutter, G. A., Fitzsimmons, J. N., Sherrell, R. M., \& Twining, B. S. (2017). Elevated trace metal content of prokaryotic communities associated with marine oxygen deficient zones: Elevated trace metals in ODZ prokaryotes. Limnology and Oceanography, 62(1), 3-25. 